\title{
Thermoregulation in free-ranging Nycteris thebaica (Nycteridae) during winter: no evidence of torpor.
}

Running title: Thermoregulation in free-ranging Nycteris thebaica

\section{Dawn Cory Toussaint ${ }^{1}$}

R. Mark Brigham ${ }^{2}$

Andrew E. McKechnie ${ }^{1, *}$

${ }^{1}$ Mammal Research Institute, Department of Zoology and Entomology, University of Pretoria, Private Bag X20, Hatfield 0028, South Africa

${ }^{2}$ Department of Biology, University of Regina, Regina, SK S4S 0A2, Canada

*Address for correspondence:

Email: aemckechnie@zoology.up.ac.za

Tel: +27-(0)12-4203232

Fax: $+27-(0) 12-3625242$

\begin{abstract}
Bats are among the most heterothermic mammals, with nearly all species investigated under free-ranging conditions to date exhibiting some degree of daily torpor and/or hibernation. We investigated thermoregulation during late winter by seven Nycteris thebaica in a warm, semi-arid habitat in northern South Africa, using temperaturesensitive transmitters to measure skin temperature $\left(\mathrm{T}_{\text {skin }}\right)$. Unexpectedly, we found no evidence for any expression of daily torpor or hibernation based on a total of 86 days of data from 7 bats (one male and six females), despite air temperatures as low as $\sim 10$ ${ }^{\circ} \mathrm{C}$. Instead, daytime $\mathrm{T}_{\text {skin }}$ was distributed unimodally with most values in the 33 -
\end{abstract}


$35^{\circ} \mathrm{C}$ range, and a minimum $\mathrm{T}_{\text {skin }}$ of $28.4^{\circ} \mathrm{C}$ at a roost temperature of $24.6^{\circ} \mathrm{C}$. There are several possible reasons why $N$. thebaica may avoid torpor, including predation in roosts, and the long nightly foraging periods of this species compared to many others.

Key words: Afrotropics; body temperature; heterothermy; Nycteridae; skin temperature

Heterothermy is a widespread physiological response by endotherms which involves the controlled lowering of the body temperature $\left(\mathrm{T}_{\mathrm{b}}\right)$ set point, with an associated reduction in metabolic rate (MR) and thus substantial energy and water savings (Geiser, 2004; Lyman et al., 1982). Mammalian heterothermy has traditionally been separated into two categories, namely daily torpor and hibernation, with minimum $T_{b}$ and MR typically lower during hibernation compared to daily torpor (Geiser et al., 1995). Recent work has countered the long held dogma that mammalian heterothermy is predominantly a temperate-latitude phenomenon, and instead supports the notion that torpor and/or hibernation is widespread in phylogenetically diverse tropical and subtropical mammalian taxa (Geiser, 1994: 2004; Lovegrove, 2012; McKechnie et al., 2011).

Bats are among the most heterothermic mammals. As small endotherms with high mass-specific rates of heat loss coupled with comparatively high energy requirements associated with flight (Harrison et al., 2000), they likely regularly face mismatches between energy supply and demand (Lyman, 1970). Moreover, many species feed on aerial insects or nectar, resources whose availability is strongly dependent on ambient temperature (Racey et al., 1985; Rydell et al., 1996). In 
temperate latitudes with long, cold winters, many non-migratory bats hibernate for much of the year, usually in thermally stable hibernacula such as caves (Park et al., 2000; Ransome, 1990). Several tropical and subtropical species are also known to hibernate and/or use daily torpor under natural conditions in winter, and in some cases summer (Coburn et al., 1996; Cory Toussaint et al., 2010; Dechmann et al., 2011; Liu et al., 2011; Stawski et al., 2010; Turbill et al., 2003).

Many gaps remain in our knowledge regarding the phylogenetic and ecological determinants of heterothermy in free-ranging tropical bats. For instance, the family Nycteridae is widespread in Africa and Asia (Thomas et al., 1994), but there are no field data available on thermoregulation for any members of this group. There is also a lack of data for species from semi-arid tropical environments; most previous work has focused on species inhabiting rainforest or mesic woodlands. Thus, our purpose was to assess the patterns of heterothermy exhibited by free-ranging Nycteris thebaica during the austral winter in a tropical semi-arid environment. This species is a clutter forager and feeds predominantly on orthopteran, coleopteran and lepidopteran insects (Monadjem et al., 2010). We predicted that, as is the case for many Australasian species, $N$. thebaica $(\sim 12 \mathrm{~g})$ would use pronounced heterothermy during the warm, dry winter months.

Our study was conducted in the private game reserve Makulu Makete (S $22^{\circ}$ 35 09' E $28^{\circ} 52^{\prime}$ ) about $30 \mathrm{~km}$ west of Alldays in the Limpopo River valley, Limpopo Province, northern South Africa. N. thebaica [body mass $=11.7 \pm 0.8 \mathrm{~g}(\mathrm{n}=7)$ ] were captured using mist nets as they exited from a day roost in the cavity of a baobab tree (Adansonia digitata) to forage between 20 July and 24 August 2010. Skin temperature ( $\left.\mathrm{T}_{\text {skin }}\right)$ was measured using temperature-sensitive transmitters weighing $\sim 0.5 \mathrm{~g}$ (BD2T, Holohil Systems, Carp ON, Canada), equivalent to $\sim 4.5 \%$ of the bats' body mass 
and calibrated against a mercury-in-glass thermometer (accuracy traceable to NIST) in a water bath over temperatures of $5-45^{\circ} \mathrm{C}$ in $5{ }^{\circ} \mathrm{C}$ increments. A transmitter was attached to each bat by clipping a small patch of fur between the scapulae and using a latex-based adhesive (Osto-Bond, M.O.C., Vaudreuil QC, Canada) to secure the transmitter in place. $\mathrm{T}_{\text {skin }}$ was measured manually using a broad-band communications receiver (IC-R10, Icom, Bellevue, WA). Data were collected hourly during the day, and every 30 minutes from $1600 \mathrm{~h}$ until the bats left the day roost to forage, as well as for two hours following arrival at the day roost. An observer waiting at the roost was able to determine the arrival times of tagged individuals by the consistent pulse strength associated with their presence in the roost, as opposed to the modulation of pulses when the bats were outside. Pulse intervals were estimated by timing 21 pulses using a stopwatch, with $\mathrm{T}_{\text {skin }}$ values estimated based on transmitter-specific calibration curves. We obtained $\mathrm{T}_{\text {skin }}$ data from 7 bats ( 1 male and 6 females). This biased sex ratio did not reflect general activity levels; we caught considerable numbers of both males and females during the study period, but were unfortunate in that most of the individuals from which we obtained data were females. $\mathrm{T}_{\text {skin }}$ is a good indicator of core body temperature $\left(\mathrm{T}_{\mathrm{b}}\right)$, particularly in bats and caprimulgid birds, but is generally $2-3{ }^{\circ} \mathrm{C}$ lower than $\mathrm{T}_{\mathrm{b}}$ in normothermic individuals (Brigham et al., 2000; McKechnie et al., 2007; Willis et al., 2003).

Temperatures in roosts $\left(T_{\text {roost }}\right)$ were recorded using miniature data loggers (Thermochron iButton, Dallas Semiconductor, Dallas, USA, resolution $\left.=0.0625^{\circ} \mathrm{C}\right)$ placed directly in day roosts as close to the roosting bats as possible, suspended so as to measure air rather than surface temperature. We did not insulate the iButtons to muffle the ultrasound they emitted (Willis et al., 2009), but as they were typically positioned $>30 \mathrm{~cm}$ from roosting bats it is unlikely that the ultrasound emissons 
Table 1. Data for seven adult Nycteris thebaica in which skin temperatures were measured telemetrically during winter 2010 in the Limpopo River valley, South Africa. "Days" indicates the number of days of data obtained from each individual, and "Period" the range of dates in 2010 during which data were collected.

\begin{tabular}{lcccccc}
\hline Sex & Body mass & Days & Period & \multicolumn{3}{c}{ Skin temperature $\left({ }^{\circ} \mathrm{C}\right)$} \\
\cline { 5 - 7 } & & & & Mean $\pm \mathrm{SD}$ & Min & Max \\
\hline Male & 10.5 & 10 & $23 / 07-05 / 08$ & $34.6 \pm 1.6$ & 30.8 & 38.3 \\
Female & 12.6 & 10 & $24 / 08-16 / 09$ & $33.7 \pm 1.4$ & 28.4 & 38.0 \\
Female & 12.1 & 12 & $24 / 08-15 / 09$ & $33.8 \pm 0.9$ & 30.6 & 37.2 \\
Female & 11.0 & 8 & $20 / 07-11 / 08$ & $34.2 \pm 1.8$ & 30.0 & 38.6 \\
Female & 12.6 & 15 & $24 / 08-09 / 09$ & $33.0 \pm 2.1$ & 29.1 & 38.3 \\
Female & 11.5 & 12 & $05 / 08-21 / 08$ & $33.9 \pm 1.6$ & 30.1 & 37.9 \\
Female & 11.9 & 19 & $22 / 08-16 / 09$ & $33.8 \pm 1.1$ & 29.2 & 37.6 \\
\hline
\end{tabular}

affected patterns of thermoregulation. Outside air temperature $\left(\mathrm{T}_{\mathrm{a}}\right)$ was also recorded using iButtons, in this case placed $1 \mathrm{~m}$ above the ground, suspended in ventilated white polystyrene cups in a shaded area in the vicinity of the day roosts. All iButtons were calibrated over a temperature range of $10-40{ }^{\circ} \mathrm{C}$ in a water bath, as outlined above.

Based on a total of 86 days of data from 7 bats, we found no evidence for daily torpor or hibernation in $N$. thebaica; only shallow $\mathrm{T}_{\text {skin }}$ decreases of $6-9{ }^{\circ} \mathrm{C}$ occurred (Figure 1), with a minimum $\mathrm{T}_{\text {skin }}=28.4{ }^{\circ} \mathrm{C}$ at $\mathrm{T}_{\text {roost }}=24.6^{\circ} \mathrm{C}$ (Figure 2). The daytime $\mathrm{T}_{\text {skin }}$ for all individuals was unimodally distributed, with the majority of values between 33 and $35{ }^{\circ} \mathrm{C}$. Overall mean $\pm \mathrm{SD} \mathrm{T}_{\text {skin }}$ was $33.8 \pm 1.6{ }^{\circ} \mathrm{C}$. On the few occasions when $\mathrm{T}_{\text {skin }}$ was reduced to relatively low levels, these reductions were transient, with no indication of any defence of a reduced $\mathrm{T}_{\mathrm{b}}$ setpoint (Figure 1). This latter pattern was observed in all individuals. $\mathrm{T}_{\text {skin }}$ remained close to normothermic levels even when $\mathrm{T}_{\text {roost }}$ was considerably lower; for instance at a $\mathrm{T}_{\text {roost }}$ of $16.5{ }^{\circ} \mathrm{C}$, the 


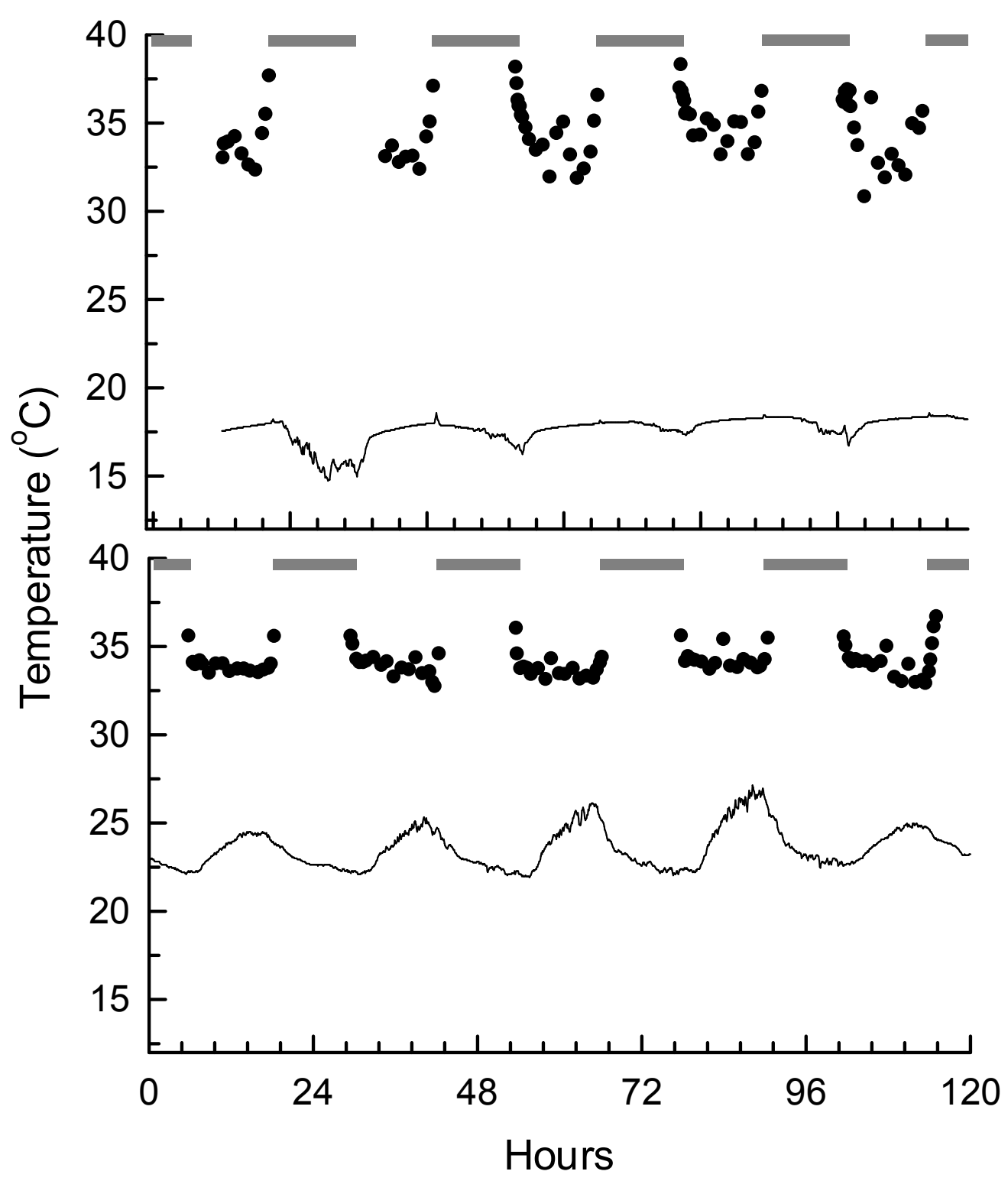

Figure 1. Representative traces of day-time (i.e., roosting) skin temperature (dots) in a male (upper panel) and female (lower panel) Nycteris thebaica and roost temperature (solid line) over five-day periods. Data for the male were recorded between 24 and 28 July, during which time he was roosting in a cavity in a baobab tree. Data for the female were recorded between 1 and 5 September while she was roosting in a shallow cave. The periods between sunset and sunrise are indicated with horizontal bars at the top of each panel.

corresponding $\mathrm{T}_{\text {skin }}$ was $30.8{ }^{\circ} \mathrm{C}$ (Figure 2). All radio-tagged bats left their day roosts every day at dusk presumably to forage, regardless of weather conditions. The 


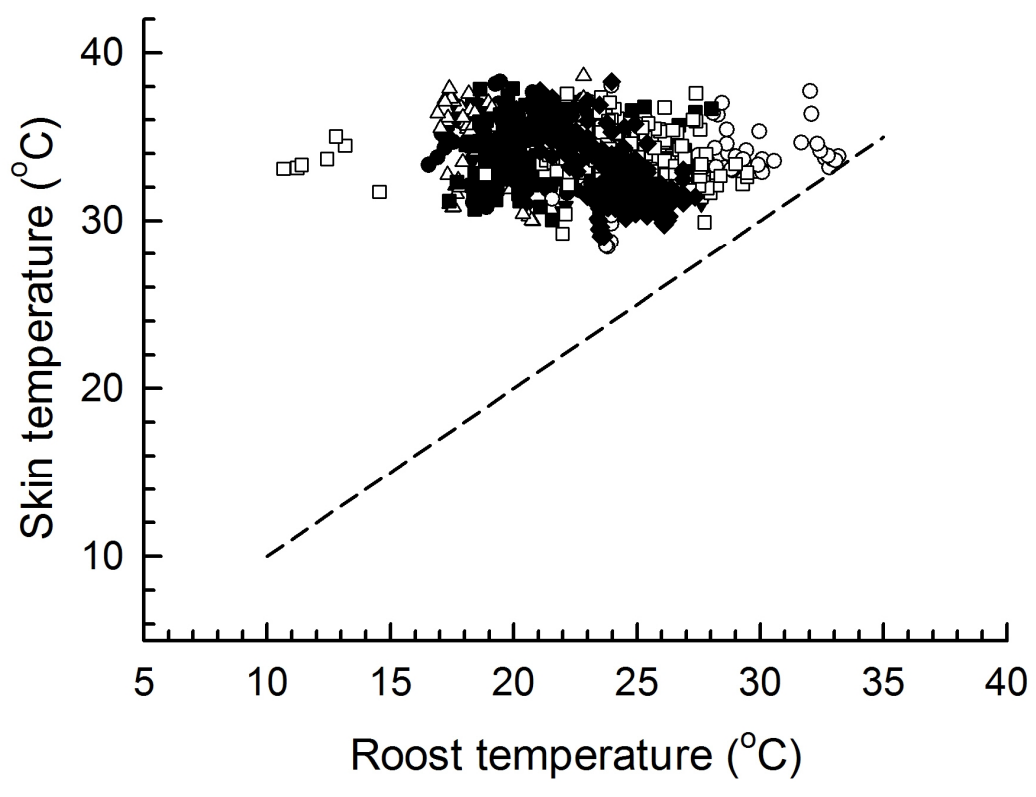

Figure 2. The relationship between skin $\left(\mathrm{T}_{\text {skin }}\right)$ and roost temperature $\left(\mathrm{T}_{\text {roost }}\right)$ in seven Nycteris thebaica individuals. Different symbols refer to different individuals, and the dashed line indicates $\mathrm{T}_{\text {skin }}=\mathrm{T}_{\text {roost }}$.

individuals from whom we obtained data regularly switched roost sites during the study period, alternating between the baobab tree cavity at which they were caught, and one of two shallow caves in nearby rocky hills (maximum distance between roosts $=3.3 \mathrm{~km})$. Repeated-measures analyses of variance indicated no significant differences in minimum $\left(F_{2,12}=1.808, \mathrm{P}=0.276\right)$, mean $\left(F_{2,12}=3.831, \mathrm{P}=0.118\right)$, or maximum $\left(F_{2,12}=0.499, \mathrm{P}=0.641\right) \mathrm{T}_{\text {skin }}$ when they used these different roosts, despite the fact that the roosts varied substantially in terms of $\mathrm{T}_{\text {roost }}$ (Figure 1). In a laboratory study, Cory Toussaint and McKechnie (in press) observed a minimum subcutaneous temperature in $N$. thebaica of $26.8^{\circ} \mathrm{C}$ at $\mathrm{T}_{\mathrm{a}}=9.9^{\circ} \mathrm{C}$, lower 
than the minimum $\mathrm{T}_{\text {skin }}$ we report here, but nevertheless not indicative of the deep heterothermy typical of most bats. The absence of pronounced heterothermy in freeranging $N$. thebaica contrasts with the general microchiropteran pattern of large reductions in $\mathrm{T}_{\mathrm{b}}$ even in species inhabiting warm subtropical habitats (Bartels et al., 1998; Cory Toussaint et al., 2010; Jacobs et al., 2007; Stawski et al., 2010; Turbill et al., 2008). For instance, Scotophilus dinganii on the subtropical east coast of South Africa used torpor while roosting in buildings, tree foliage and tree cavities, even though $\mathrm{T}_{\mathrm{a}}$ remained above $\sim 15^{\circ} \mathrm{C}$ (Jacobs et al., 2007). Other species inhabiting warm environments in northern and eastern South Africa such as Mops condylurus and Sauromys petrophilus are highly heterothermic under laboratory conditions and become torpid even when $\mathrm{T}_{\mathrm{a}}>20^{\circ} \mathrm{C}$ (Cory Toussaint et al., in press; Maloney et al., 1999).

A number of bat species in subtropical Australia are highly heterothermic (Stawski et al., 2010; Turbill et al., 2008; Turbill et al., 2003), and recent work in tropical central America has revealed that Molossus molossus maintains an almost continuous hypometabolic state (Dechmann et al., 2011). In subtropical Taiwan, Hipposideros terasensis hibernates at $\mathrm{T}_{\text {roost }}>22{ }^{\circ} \mathrm{C}$ for up to 72 days and is the largest bat known to hibernate (Liu et al., 2011). Although (McNab, 2008) listed a number of tropical and subtropical bat species as not using torpor, most of these species were studied under laboratory conditions, and such data often do not provide a reliable indication of heterothermy under natural conditions (Geiser et al., 2000).

There are several possible reasons for the lack of pronounced heterothermy in $N$. thebaica. First, in parts of its range $N$. thebaica may face a relatively high risk of predation. It is known to be eaten by Nycteris grandis, which likely captures individuals while they roost (Fenton et al., 1993). Vulnerability to predation while in 
a lethargic, non-responsive state is widely viewed as one of the most significant ecological costs of heterothermy, although some mammals retain partial locomotor ability even at $\mathrm{T}_{\mathrm{b}}$ far below normothermy (Choi et al., 1998; Rojas et al., 2012). However, the range of $N$. grandis is not known to extend into our study area (Monadjem et al., 2010), although little information exists on other potential predators of roosting $N$. thebaica (Monadjem et al., 2010; Skinner et al., 2005). A second possibility is that the need for energy conservation via heterothermy is obviated by communal roosting. Endotherms can save substantial fractions of their rest-phase energy expenditure by roosting in close contact with conspecifics (e.g., (Boix-Hinzen et al., 1998; McKechnie et al., 2001). We were unable to observe $N$. thebaica while roosting, but individuals of this species are known to roost fairly far apart (Skinner et al., 2005), arguing against communal roosting driving the absence of heterothermy.

A third possible explanation concerns reproduction. In southern Africa, copulation and fertilization in N. thebaica occurs in June (Bernard, 1982), thus reproductive females would have been in early stages of pregnancy during our study. However, the absence of heterothermy in a free-ranging male as well as the females, as well as the similarity of minimum $\mathrm{T}_{\text {skin }}$ values here and in a lab study where most individuals were males (Cory Toussaint et al., in press), argues against this being the sole determining factor. Finally, the nightly foraging period of $N$. thebaica individuals was relatively long compared to other species. Bats spent an average period of $11.45 \pm 0.65 \mathrm{hr}(\mathrm{n}=60$ nights $)$ away from the day roost, with only a few hours each night spent in a night roost (D. Cory Toussaint pers $o b$.). In comparison, average nightly foraging time in M. molossus in Panama was only 37 min (Dechmann et al., 2011). The long nightly foraging bouts of $N$. thebaica suggest that to overcome potential energetic shortfalls, this species spends long periods searching for prey. 
These long foraging bouts, combined with mild roost thermal conditions, may impose limits on the time available for and thermal conditions necessary to employ pronounced heterothermy. Whatever the reasons for the lack of pronounced heterothermy, the fact that our data suggest it is avoided by this species warrants further consideration given that most bats, even in warm regions, employ it regularly (Stawski et al., 2009; Turbill et al., 2003).

\section{Acknowledgements}

We thank Peter and Jane Phillips for allowing us to work on their property, and the following field assistants: Cedric and Yvonne Cory Toussaint, Anne Brigham, Hermann Müller and Philip Jordaan. We also thank two anonymous reviewers for their constructive comments. This research was funded by Bat Conservation International and the National Research Foundation, and all procedures were approved by the University of Pretoria's Animal Use and Care Committee (EC014$10)$.

\section{References}

Bartels, W., Law, B.S., Geiser, F., 1998. Daily torpor and energetics in a tropical mammal, the northern blossom bat Macroglossus minimus (Megachiroptera). J. Comp. Physiol. B 168, 233-239.

Bernard, R.T.F., 1982. Female reproductive cycle of Nycteris thebaica (Microchiroptera) from Natal, South Africa. Z. Säugetierk.47, 12-18.

Boix-Hinzen, C., Lovegrove, B.G., 1998. Circadian metabolic and thermoregulatory patterns of red-billed woodhoopoes (Phoeniculus purpureus): the influence of huddling. J. Zool., Lond. 244, 33-41. 
Brigham, R.M., Körtner, G., Maddocks, T.A., Geiser, F., 2000. Seasonal use of torpor by free-ranging Australian owlet-nightjars (Aegotheles cristatus). Physiol. Biochem. Zool. 73, 613-620.

Choi, I.-H., Cho, Y., Oh, Y.K., Jung, N.-P., Shin, H.-C., 1998. Behavior and muscle performance in heterothermic bats. Physiol. Zool. 71, 257-266.

Coburn, D.K., Geiser, F., 1996. Daily torpor and energy savings in a subtropical blossom-bat, Syconycyeris australis (Megachiroptera). In: Geiser, F., Hulbert, A.J., Nicol, S.C. (Eds.), Adaptations to the cold: Tenth International Hibernation Symposium. University of New England Press, Armidale, pp. 3945.

Cory Toussaint, D., McKechnie, A.E. in press. Interspecific variation in thermoregulation among three sympatric bats inhabiting a hot, semi-arid environment. J. Comp. Physiol. B

Cory Toussaint, D., McKechnie, A.E., Van der Merwe, M., 2010. Heterothermy in free-ranging male Egyptian Free-tailed bats (Tadarida aegyptiaca) in a subtropical climate. Mamm. Biol. 75, 466-470.

Dechmann, D.K.N., Ehret, S., Gaub, A., Kranstauber, B., Wikelski, M., 2011. Low metabolism in a tropical bat from lowland Panama measured using heart rate telemetry: an unexpected life in the slow lane. J. Exp. Biol. 214, 3605-3612.

Fenton, M.B., Rautenbach, I.L., Chipeses, D., Cumming, M.B., Musgrave, M.K., Taylor, J.S., Volpers, T., 1993. Variation in foraging behaviour, habitat use, and diet of large slit-faced bats (Nycteris grandis). Z. Säugetierk. 58, 65-74.

Geiser, F., 1994. Hibernation and daily torpor in marsupials: a review. Australian J. Zool., Lond. 42, 1-16.

Geiser, F., 2004. Metabolic rate and body temperature reduction during daily torpor. 
Ann. Rev. Physiol. 66, 239-274.

Geiser, F., Holloway, J.C., Körtner, G., Maddocks, T.A., Turbill, C., Brigham, R.M., 2000. Do patterns of torpor differ between free-ranging and captive mammals and birds? In: Heldmaier, G., Klingenspor, M. (Eds.), Life in the cold: 11th International Hibernation Symposium. Springer, Berlin, pp. 95-102.

Geiser, F., Ruf, T., 1995. Hibernation versus daily torpor in mammals and birds: physiological variables and classification of torpor patterns. Physiol. Zool. 68, 935-966.

Harrison, J.F., Roberts, S.P., 2000. Flight respiration and energetics. Ann. Rev. Physiol. 62, 179-205.

Jacobs, D.S., Kelly, E.J., Mason, M., Stoffberg, S., 2007. Thermoregulation in two free-ranging subtropical insectivorous bat species: Scotophilus species (Vespertilionidae). Can. J. Zool. 85, 883-890.

Liu, J.-N., Karasov, W.H., 2011. Hibernation in warm hibernacula by free-ranging Formosan leaf-nosed bats, Hipposideros terasensis, in subtropical Taiwan. J. Comp. Physiol. B 181, 125-135.

Lovegrove, B.G., 2012. The evolution of endothermy in Cenozoic mammals: a Pleisiomorphic-Apomorphic continuum. Biol. Rev. 87, 128-162.

Lyman, C.P., 1970. Thermoregulation and metabolism in bats. In: Wimsatt, W.A. (Eds.), Biology of bats. Academic Press, New York, pp.

Lyman, C.P., Willis, J.S., Malan, A., Wang, L.C.H., 1982. Hibernation and torpor in mammals and birds. Academic Press, New York.

Maloney, S.K., Bronner, G.N., Buffenstein, R., 1999. Thermoregulation in the Angolan free-tailed bat Mops condylurus : a small mammal that uses hot roosts. Physiol. Biochem. Zool. 72, 385-396. 
McKechnie, A.E., Ashdown, R.A.M., Christian, M.B., Brigham, R.M., 2007. Torpor in an Afrotropical caprimulgid, the Freckled Nightjar (Caprimulgus tristigma). J. Avian Biol. 38, 261-266.

McKechnie, A.E., Lovegrove, B.G., 2001. Thermoregulation and the energetic significance of clustering behavior in the white-backed mousebird (Colius colius). Physiol. Biochem. Zool. 74, 238-249.

McKechnie, A.E., Mzilikazi, N., 2011. Heterothermy in Afrotropical birds and mammals: a review. Int. Comp. Biol. 51, 349-363.

McNab, B.K., 2008. An analysis of the factors that influence the level and scaling of mammalian BMR. Comp. Biochem. Physiol. A 151, 5-28.

Monadjem, A., Taylor, P.J., Cotteril, F.P.D., Schoeman, M.C., 2010. Bats of southern and central Africa. Wits University Press, Johannesburg.

Park, K.J., Jones, G., Ransome, R.D., 2000. Torpor, arousal and activity of hibernating greater horseshoe bats (Rhinolophus ferrumequinum). Funct. Ecol. $14,580-588$.

Racey, P.A., Swift, S.M., 1985. Feeding ecology of Pipistrellus pipistrellus (Chiroptera, Vespertilionidae) during pregnancy and lactation. I. Foraging behavior. J. Animal Ecol. 54, 205-215.

Ransome, R.D., 1990. The natural history of hibernating bats. Christopher Helm, London.

Rojas, A.D., Körtner, G., Geiser, F., 2012. Cool running: locomotor performance at low body temperature in mammals. Biol. Lett. $8,868-870$.

Rydell, J., Entwistle, A., Racey, P.A., 1996. Timing of foraging flights of three species of bats in relation to insect activity and predation risk. Oikos 76, 243252. 
Skinner, J.D., Chimimba, C.T., 2005. The mammals of the southern African subregion. 3rd Ed. Cambridge University Press, Cambridge.

Stawski, C., Geiser, F., 2010. Seasonality of torpor patterns and physiological variables of a free-ranging subtropical bat. J. Exp. Biol. 213, 393-399.

Stawski, C., Turbill, C., Geiser, F., 2009. Hibernation by a free-ranging subtropical bat (Nyctophilus bifax). J. Comp. Physiol.B 179, 433-441.

Thomas, N.M., Harrison, D.L., Bates, P.J.J., 1994. A study in the genus Nycteris (Mammalia, Chiroptera, Nycteridae) with consideration of its taxonomic importance. Bonner Zoologische Beiträge 45, 17-31.

Turbill, C., Geiser, F., 2008. Hibernation by tree-roosting bats. J. Comp. Physiol. B $178,597-605$.

Turbill, C., Law, B.S., Geiser, F., 2003. Summer torpor in a free-ranging bat from subtropical Australia. J. Therm. Biol. 28, 223-226.

Willis, C.K.R., Brigham, R.M., 2003. Defining torpor in free-ranging bats: experimental evaluation of external temperature-sensitive radiotransmitters and the concept of active temperature. J. Comp. Physiol. B 173, 379-389.

Willis, C.K.R., Jameson, J.W., Faure, P.A., Boyles, J.G., Brack, V., Cervone, T.H., 2009. Thermocron iButton and iBBat temperature dataloggers emit ultrasound. J. Comp. Physiol. B 179, 867-874. 